\title{
A World Apart: How Distance Education Can Effectively Reach Around the Globe
}

\author{
Joseph J. Frantiska Jr. \\ Walden University
}

\begin{abstract}
Distance education has revolutionized the field of education by giving faculty the ability to reach students anywhere on Earth. In many cases, the distances between faculty and students can be rather large with associated opportunities and challenges. An obvious challenge is the need for timely communications between faculty and students as well as among the students themselves. This can be compounded if the nature of the course requires widely dispersed students to work together as a group with the transfer of documents and frequent communications driven by deadlines as well as the desire to produce a complete document that adheres to all requirements.
\end{abstract}

Keywords: distance education, asynchronous, student collaboration, social constructivism

\section{Introduction}

In today's world, there are a number of indications that technology has changed how information is exchanged; a 24-hr news cycle and the World Wide Web are a couple of the most notable. A common application of the World Wide Web is that of distance education. Online faculty members have become accustomed to the challenges and rewards of teaching online in an asynchronous distance learning model. However, what can happen if the distances are at an extreme?

In the majority of courses, the geographical distances are large but manageable as they do not cross a large number of time zones. This article details the conduct of an instructional design course in 2010 where the distances were indeed at an extreme. In this 8-week graduate level course, about $60 \%$ of the students were scattered throughout North America with the remainder in Sri Lanka-11 to 14 time zones apart.

While it is common for online courses to have a widely scattered cadre of students, this one was different in a couple of ways. First, in addition to the aforementioned geographical disparity, the instructional design course is requires the students to work on a course project as a team with five students being the optimal grouping. Each team needs to be comprised of people who have talents that can be applied to an aspect of the project. Second, because of the need for people of particular talents, they may not be in the same local geographical area. This might mean different parts of the country as in many online courses but in this situation it could also mean different ends of the globe. Of course, the most important aspect of working as a team is communications. It is even more critical when the participants have never worked together and must do so within a limited timeline for a common goal. Add to that the inability to see each other with the associated helpful visual/aural cues such as body language or speech inflections and the coordination of the team is also paramount. All of the Sri Lankan students had a good command of the English language, so there were no significant problems with grammar or diction. 


\section{Literature Review}

The extreme distances and the need for group members with specific talents necessitated a review of the literature with regards to member selection and project assessment. The selection of the group members can be the first and possibly most difficult problem in online group projects. There can be two primary solutions to this problem: selecting at random or selecting based on geographic or other factors (Roberts \& McInnerney, 2007). The implication of these solutions in this study is heightened due to the extreme distance between the two main groups. The question of how best to balance the need for people with required skills within a specific group and to limit the distance between the group members proved to be difficult.

Also, the question of how to assess the performance of each member with each group can be difficult. Morgan, Williams, Cameron, and Wade (2014) proposed assigning a specific role to each group member as one solution to this problem. It is also important to develop a mechanism to individualize the grades as well as to see how they contribute to the group project as a whole (Roberts \& McInnerney, 2007).

As an overall solution to the problem of how to assess the performance of groups and the individual group members, Brindley, Blaschke, and Walti (2009) recommended transparent expectations and clear instructions. Transparent expectations refer to making the expectations of the group dynamics as they relate to collaborative learning being made very clear to the learners at the course outset. Also, at the beginning of the course, clear instructions regarding the group project, timelines, and individual group member responsibilities need to be described in detail. This allows students to focus on collaborating on the overall project goals and their part in it instead of spending a lot of time trying to clarify and understand these points.

Another solution to this problem that was employed was to have a different group member act as the group leader each week. One of the group leaders' duties for the week was to create and submit to the instructor a group progress report, with the contributions of each group member to the group project as well as the progress of the project as a whole, as proposed by Soon and Fraser (2011). One benefit of this approach is that peer assessment can cause "slacking" students to be more attentive and increase their future contributions in both quantity and quality where applicable (Jacobs, 2014). An added benefit of this approach is for all group leaders to use a standardized rubric to give consistency in grading (Williams, Cameron, \& Morgan, 2012).

Paulus (2005) suggested that in line with this is to foster interdependence among the group members. This is not to say that the group members should be so dependent upon each other that they do each other's job. Instead, as Paulus stated, "Throughout the syllabus it was emphasized that students should work together for success, and not rely on the instructor to direct the group's interaction" (p. 125). So interdependence among the group members is meant as a form of selfdirection for the group as a whole. Of course, the instructor still needs to be present in the form of initial direction and instructions

\section{The ADDIE Model and Its Repercussions}

After welcoming the students, it was imperative to inquire as to their applicable experience and desired position in a group. Then each was reviewed so that as many people as possible could be in the position they wanted as well as filling all positions within each group. The instructional design course uses the analysis, design, development, integration, and evaluation (ADDIE) model of instructional design. ADDIE is a classic instructional design process that encompasses the entire development lifecycle. As previously stated, each phase requires specific expertise and one student in each group is responsible for a particular phase of the process. While this would be true of the conduct of this course regardless of the geographical disparity of the students, in this specific 
instance the large distances span numerous time zones. Therefore, a possible dilemma with regard to the composition of the groups can ensue when trying to balance the needed group expertise with the geographic locations of the students. The easy way to create the groups would have been to put all of the Sri Lankan students in their own groups. However, the positions in all groups may not be populated with the best possible person. Thus, the members of some groups may be from the United States and Sri Lanka, creating potential problems with regards to timely and efficient communications.

While there were some groups with a large degree of geographic dispersion, others would be more limited, so another potential problem of the widely varying degree of timely communications (or lack thereof) can arise. Additionally, the ADDIE model is also called the waterfall model. This name results from the fact that the input to each phase is the output of the previous phase. That is, each product of a phase cascades or flows into the next phase like a waterfall, as depicted in Figure 1.

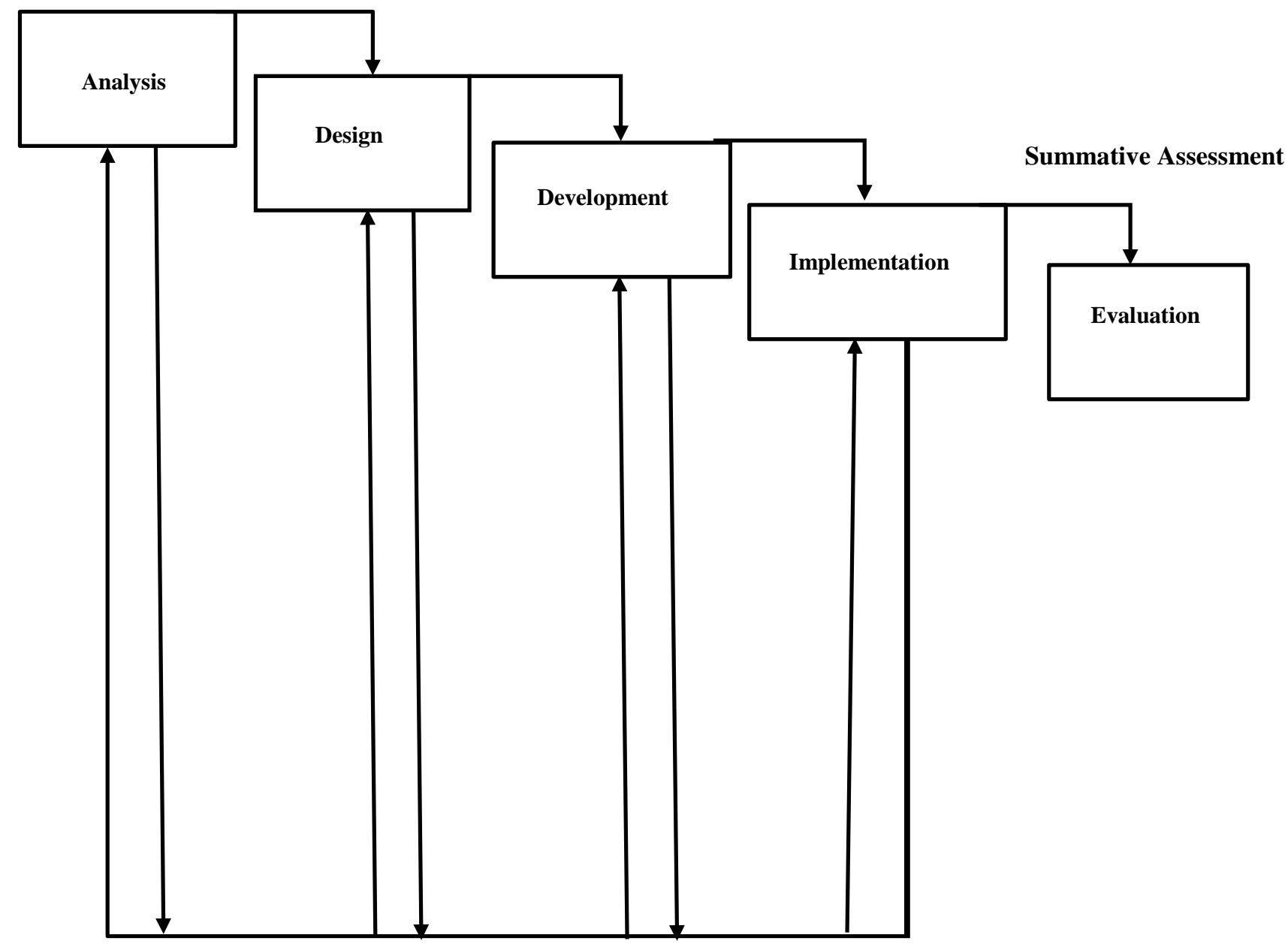

Formative Assessment

Figure 1. The Classic ADDIE Model 
The multiple-phase approach of the ADDIE model requires assessment at each phase as well as at the project completion. Therefore, two types of assessment were used: formative and summative. Formative assessment is the process by which the results of evaluation can be fed back into the model thereby refining the process and increasing its accuracy. As Gagne and Briggs (1979) stated, "Formative evaluations provide data on the basis of which to revise and improve the materials, the lesson plans, the performance tests, and indeed the operation of the entire instructional system" (p. 37). As the system is completed, an evaluation that documents the extent to which the training program meets the organization's needs is conducted. This is called a summative assessment. "Summative evaluation is usually undertaken when development of an instructional entity is in some sense completed, rather than ongoing. Its purpose is to permit conclusions to be drawn about how well the instruction has worked" (p. 293).

\section{Problems and Solutions}

In summary, the potential problems in this course are as follows:

- Varying degree of student geographical disparity within groups

- Timeliness of communications

- ADDIE model requires sequential connection, and therefore dependency, between phases.

The first problem of varying geographical disparity is at the root of the other problems of this course: the need to have students with the appropriate talents, regardless of location, spread across all groups so that each has a fair and equal opportunity to succeed in the course. To help communications among group members, within the virtual classroom, each group has a group project discussion board, a Wiki, and a Dropbox to exchange papers, documents, and so forth. Each phase of the project that is to be created will mirror the ADDIE model phases of analysis, design, development, integration, and evaluation. Each phase will be fulfilled by a student who has displayed the appropriate ability and desire to complete that phase. The first 2 weeks are composed of a course introduction and the assembly of the project groups with the specific student roles, while the eighth and final week is largely concerned with the delivery of the final group document and a conclusion to the course. In Weeks 3 through 7, each phase will be documented by the completion and posting to the group Wiki of a document detailing the progress and development of that project phase, as seen in Table 1. These documents also act as milestones to keep the project on schedule with the overall deadline being the end of the course. They also can be used by the facilitator in conjunction with the weekly group progress reports as a means by which to assess not only the group progress, but also that of the individual members.

Table 1. Course Weekly Documents and Their Contents

\begin{tabular}{|c|c|}
\hline Week & Document \\
\hline 3 & $\begin{array}{l}\text { Analysis document: Project description, needs analysis, learner analysis, } \\
\text { performance gap analysis, contextual analysis, and unit goals }\end{array}$ \\
\hline 4 & $\begin{array}{c}\text { Design document: Sequencing description, instructional message, strategies table, } \\
\text { text design, and multimedia design }\end{array}$ \\
\hline 5 & $\begin{array}{l}\text { Development guide: Instructional materials in draft form, the delivery } \\
\text { methodology, and the instructional plan }\end{array}$ \\
\hline 6 & $\begin{array}{c}\text { Implementation plan: Instructional unit overview, preimplementation } \\
\text { preparations, the instructional environment, the instructional } \\
\text { delivery/sequencing, and the learning assessment }\end{array}$ \\
\hline 7 & $\begin{array}{c}\text { Evaluation plan: Evaluation process, the alignment of unit goals to the evaluation } \\
\text { process, and the final document preparation }\end{array}$ \\
\hline
\end{tabular}


Because the students are unknown to each other at the course start, it is the responsibility of the facilitator to assess the abilities of the students to formulate the groups. The facilitator becomes aware of the individual student talents by directing them on the first day of class to enter a special discussion area to determine what their experiences and abilities are relevant to the group project. In turn, the facilitator attempts to fill the groups with the proper members, with the foremost reason being the appropriate group composition to afford the group the greatest chance for success. However, the morale of the individual members must also be of concern, as the facilitator needs to try to assign members to roles that they desire and will therefore give their best effort to.

Tools such as Wikis and discussions forums have been found to be very useful with widely separated group members both in tracking and understanding their individual responsibilities but also in fostering a greater understanding of the required shared responsibilities (Kear, Donelan, \& Williams, 2014).

To mediate the first problem of extreme geographic dispersion, a two-pronged approach was adopted. First, the members of each group were required to discuss amongst themselves to arrive at how best to communicate. Some exchanges on the group project discussion boards were as follows (student names, phone numbers, and state locations have been changed):

Cindy (North America): "I know we are all working in different time zones which will make our project more challenging for all of us to meet our target times. May be we can pick a standard time which all of us can meet virtually? How many hours ahead are you?"

Mahela (Sri Lanka): "I think we are nearly 10-11 hours ahead!! We faced this problem during previous discussions. Your idea is great, if we can fix a time period which convenient to all of us, then we can actively participate."

Ellen (North America): "So everyone has posted their thoughts-I think Mahela is in a time zone ahead of us and it is already tomorrow. We have got to get an IM going where at least 3 of can converse."

Sometime later that day...

Alice (North America): "Mahela is posting the wiki page per the instructions from week 2 Next Step section then once she sets it up she gives us the information and we have to post an introduction but it is only supposed to be one page for the group :) Also, Mahela I think is 10 hours ahead of Eastern Standard Time, I have been communicating in the day time because my schedule is flexible right now. I am in Virginia and if I figure correctly if I post between $8 \mathrm{am}-11$ am it will not be too late (or early in Mahela's time zone). So, I believe Mahela's post has to almost be a day early."

Another group whose members were all in North America decided to use a conference call or classroom chat, as they were within a reasonable number of time zones of each other:

Shirley (North America): "Is there any way that we can make a conference call so that we can be on the phone at the same time or maybe we can use the classroom chat so that we can all converse at the same time to alleviate some of the confusion?"

Ruth (North America): "I am available to talk on the phone in the next hour or so. If you see this posting feel free to call me at 888-555-5678. The time is now 11:45 A.M. PST."

Jane (North America): "Also, I am in for a conference call but I need so notice considering that I sub all day then go to Sylvan Learning Center from 3-8pm ET. I think that call would be great because realistically I feel like I have no idea what we are doing nor have an 
objective. 888-555-1234 is my number and I think that the Chat would be super perfect considering that it is one of our tabs."

In another group, a hybrid solution of real-time and non-real-time communications was used because one member was unable to use the real-time communications with the others:

Theresa (North America): "I am in Boston, Massachusetts. Although, with an 11 hour time difference, I cannot think of a time that is going to be convenient to us both. In addition, it is now Wednesday and according to the schedule we were to have collaborated by now on ideas. At this point, since you four are all at least in the same time zone, is it possible for you all to at least get together and talk about the project in real-time in Chat? I can then read the chat archive transcript and follow any direction you work out."

The second portion of the approach was to require each group member to time stamp their course assignment submissions. The time stamp was to be comprised of the full date (month, day, and year) as well as the time in hours:minutes:seconds. Therefore, the importance of individual accomplishment and responsibility is highlighted as well as those for the group itself (Wang, 2014). This was useful to the students as seen in a message from a group member in North America to a fellow member in Sri Lanka on their group project discussion board:

Tom (North America): "Hi Seetha; Perhaps you could email the professor and just indicate where on the Wiki your file is located. He'll be able to see by the timestamp that it was handed in on time. Take Care, Tom"

The second problem of communications timeliness, as previously stated, is rooted in the first problem of geographic dispersion. As in all courses-whether they are online, in-person, or hybrid — the need for appropriate and reasonable deadlines for assignments is obvious and necessary. In such a course with extreme time differences, such deadlines were implemented not only to assure that assignments were turned in on time and to penalize late assignments fairly, but also to provide a means to allow the group members to acquire needed documents from others in a timely manner. This is critical, as it will not only aid the students in gaining the information necessary in completing the course objectives with regards to assignments, but also with further development of the skills necessary with being part of a global team. They will find increased ability in communication/written formats, negotiating, and motivating others in a positive manner. The only way of achieving this is through actual experience and practice (Marino \& Warner, 2014).

The problem of timely communications can impact not only the students individually but also their role as a group member. Additionally, each group member takes a turn as the group project leader. As such, they are responsible for assuring that each group member fulfills their role and received a weekly progress report from each member. In turn, the group leader creates a group progress report and submits it to the course instructor. Thus, there are administrative documents as well as course materials that require adherence to deadlines and can be impacted by the timeliness of the communications.

The ADDIE model's strict structure presents another problem, as it requires that the activities and associated documents be completed correctly the first time because there is little leeway for remediation. Therefore, all of the problems impact each other, requiring an overall solution in addition to a specific solution tailored to each problem's unique requirements. With such a close relationship between these problems, the solutions themselves are closely related.

Obviously, the already-strict requirements for completed documents to be sent among group members and from the group leader to the instructor are compounded by the large time zone differences. Some exchanges between group members in North America and Sri Lanka in different groups show the understanding of the importance of both individual and group contributions: 
Anita (North America): "Deepika and Group...After reading the Analysis Document for the coming week I think any compromises and tweaking should be or can be formed from our individual and collective task with each of these documents. I think the Learning Module I proposed can be tailored to fit everyone's input and meet our necessary requirements. Deepika it is getting late where I am so if no one else's post feedback you should be able to use this as a starting point for your week's task :)"

Tasha (North America): "I am week four's project leader. My duties this week include 1. Uploading the Design Document to the Wiki site (I did this two weeks ago).

2. By Wednesday, each one of us will respond to individual parts of the Design Document.

3. By Friday, each of us will post our individual part to the Wiki site.

4. By Sunday, I will ensure that all sections read as one coherent piece by requesting revisions from you, if necessary."

This aspect of having and understanding the importance of both group and individual contributions filtered down to a group's project which consisted of a short course to teach people how to avoid foreclosure:

Sheila (North America): "Hi Keshi; Great job! The participants will be provided with a graphic organizer, which they could print out, for them follow along the instructional materials. I was wondering if we should have some type of group participation. It seems like the participants work alone most of the time, maybe we can add a component where they can work in a group or with a partner or do a role play. I also think the participants should receive some kind of certificate once they complete the program; nothing big just something they can take home to fill a sense of accomplishment. I can make one up. What do you all think?"

The most critical areas are the analyze and design phases, as they lay down the groundwork for the rest of the phases as well as the final product (Strickland, Strickland, Wang, Zimmerly, \& Moulton, 2013). Therefore, the associated analysis and design documents are arguably the most critical documents in the development of the group project. The group Wiki proved to be a critical tool in allowing all group members to contribute to each document and allowing the other members to see and comment on their work.

With the use of timestamps, discussion forums, Wikis, and group-imposed rules, the communications among the group members became relatively routine, with members falling into place knowing that these tools would make their lives easier and more efficient. The only significant discussions about the documents once the content was established were regarding formatting. While this is important due to the necessity of structure and readability, the imposed tools allowed the group members to interact in a timely and effective manner with few problems.

\section{Paradigms and Implications}

The underlying pedagogical approach to this course is constructivism. A constructivist approach fits the group-project-based courses such as instructional design, as it adheres to the principles of constructivism.

Peter Doolittle (1999) developed a list of eight constructivist principles that is largely agreed upon as valid by practitioners of this paradigm. The instructional design course was conducted so that it fits these principles, as seen in Table 2. 
Table 2. The Guiding Principles of Constructivism and the Application of Them to the Course Conduct

\begin{tabular}{|c|c|}
\hline Constructivism Principle & Course Conduct as a Result \\
\hline $\begin{array}{l}\text { Learning should take place in authentic and } \\
\text { real-world environments. }\end{array}$ & The subject matter of the course is widely employed. \\
\hline $\begin{array}{l}\text { Learning should involve social negotiation and } \\
\text { mediation. }\end{array}$ & $\begin{array}{l}\text { The group-project approach of the course provides a } \\
\text { significant amount of these interactions. }\end{array}$ \\
\hline $\begin{array}{l}\text { Content and skills should be made relevant to } \\
\text { the learner. }\end{array}$ & $\begin{array}{l}\text { Students gain proficiency in knowledge and skills that } \\
\text { are highly applicable in their future coursework and } \\
\text { employment. }\end{array}$ \\
\hline $\begin{array}{l}\text { Content and skills should be understood } \\
\text { within the framework of the learner's prior } \\
\text { knowledge. }\end{array}$ & $\begin{array}{l}\text { The students have all taken courses online and now } \\
\text { see how they should best be developed. }\end{array}$ \\
\hline $\begin{array}{l}\text { Students should be assessed formatively, } \\
\text { serving to inform future learning } \\
\text { experiences. }\end{array}$ & $\begin{array}{l}\text { Through peer feedback as well as instructor feedback, } \\
\text { the students are assessed at all points in the course. }\end{array}$ \\
\hline $\begin{array}{l}\text { Students should be encouraged to become self- } \\
\text { regulatory, self-mediated, and self-aware. }\end{array}$ & $\begin{array}{l}\text { In addition to the peer and instructor feedback, } \\
\text { learners develop these qualities by interacting with } \\
\text { their group members, also by having to complete } \\
\text { their individual assignments as well as impacting } \\
\text { and being impacted by the participation in the } \\
\text { group project assignment. }\end{array}$ \\
\hline $\begin{array}{l}\text { Teachers serve primarily as guides and } \\
\text { facilitators of learning, not instructors. }\end{array}$ & $\begin{array}{l}\text { The instructor's role in the group project and } \\
\text { discussion forums is primarily that of a facilitator. }\end{array}$ \\
\hline $\begin{array}{l}\text { Teachers should provide for and encourage } \\
\text { multiple perspectives and representations of } \\
\text { content. }\end{array}$ & $\begin{array}{l}\text { The students are allowed to not only express their } \\
\text { views in the discussions forums, but also to listen to } \\
\text { and attempt to understand those of their fellow } \\
\text { students; also, students are directed to develop } \\
\text { their project based upon the consensus of the group } \\
\text { members. }\end{array}$ \\
\hline
\end{tabular}

Psychologist Lev Vygotsky (1978) viewed the construction of knowledge to be a result of the social interaction with others via verbal and other means. Through this paradigm, he founded the theory of social constructivism. He maintained that language is used as a tool to create meaning. In addition to the interaction of students among themselves in discussion forums, a mediator (the instructor in this case) who keeps the discussion focused gives them a sense of ownership over the knowledge. All of this occurs while working within the framework of the required course objectives (Churcher, Downs, \& Tewksbury, 2014)

To that end, the course falls deep within these constructs, but how does this help to achieve the stated need of managing a distance education course whose distances are at an extreme?

Essentially, the course would be difficult to teach otherwise. The group project dictates the conduct of this course in that while discussion forums require social interaction in voicing opinions and thoughts, the group project requires the students to work closely together to achieve a common goal, with timely communications and exchange of documents being vital. Of course, this would be true if the students were in different rooms let alone different hemispheres. But the extreme distance impacts the timeliness of the interaction. Also, with respect to the aforementioned need for timely delivery of documentation amongst group members, the social interaction becomes even more intense, as the document is a tangible element of the course that captures input from the members 
and has associated with it a deadline. Also, because the documents are dependent upon one another, they represent a chain of events that is highly dependent on the efficiency of the members. This can create more anticipation and stress.

\section{Analysis}

The primary concern of this course, as with any course, is the engagement and subsequent learning of the students. With any distance learning course, there are problems that the face-to-face course will not need to address. However, the extreme distance covered by the course discussed here creates additional problems in the areas of logistics, discipline and communications. With the great degree of geographic disparity, the role of the facilitator is paramount. Of course, teachers have been the linchpin for classes for all time but the comparatively recent invention of computer-based distance education makes them as important as ever. The facilitator of this extreme distance course needed to do the following.

Establish rules of conduct for the group members: Regardless of the distance between members of a group, rules of conduct that emphasize cooperation, fairness, and civility must be created by the facilitator. It is the facilitator's responsibility to establish these rules so that the students can concentrate on the project at hand. In the case of this course, with the large number of time zones separating some students in conjunction with the comparatively short 8-week semester, time is especially of the essence and any problems of conduct can adversely impact the project as well as the individual student(s).

Assess the abilities of each student as to his or her role and group: The facilitator must take responsibility for this because there is little time for group formulation in the 8week course format. Also, students may tend to want to be in the same group as friends, compromising the required diversity of talent in the group.

Establish the required project documents to act as milestones: Not only will these documents act as milestones for the assessment of the project development, but they will also demonstrate the contributions of each student via a tangible product. Without these checkpoints, there will no clear picture of how the projects and their contributors are progressing. Finally, these documents can aid in establishing and communicating two critical points of group work that Williams et al. (2012) stressed: establish the essential task within a realistic timeline.

Establish a rotating weekly project leader for each group: In conjunction with the aforementioned project documents/milestones, the concept of a weekly rotating project leader provides a more personal assessment of each group member and their degree of contribution. Rotating the position of group project leader allows all members to serve in this position, which aids in establishing impartiality in the assessment process. Jacobs (2014) stressed the importance of peer assessment in reducing the possibility of students "slacking," but the instructor needs to assess these reviews to achieve true impartiality.

Impose the requirement that strict deadlines be observed: The extreme distances and therefore time differences in this course necessitate adherence to strict deadlines. This applies not only to the completion of project documents and tasks, but also to discussion postings as well. This is part of setting clear goals, which Paulus (2005) defined as participating "in the collaborative process for a defined length of time to complete a specified task" (p. 125). 
Might there be any alternative way to more efficiently teach the course? An obvious possibility would have been to compose the groups based upon student location so that there would be a minimal impact from the time differences, but it was looked upon as more important to get the best qualified person for each position available. This is in concert with Roberts and McInnerney (2007), who viewed assessing each student's academic and work qualifications as the primary factor in deciding group formation.

Another possible way to have made the course easier to conduct would have been to combine some of the documents. But if this were done, the phases of the ADDIE model would not be seen as distinct entities, each of which asks and answers specific questions along the way to arriving at a solution to the problem of developing a course as efficiently and accurately as possible. That is, the milestones will not properly signal the division between project development phases.

\section{Conclusion}

This course is simultaneously a microcosm of online courses and an extreme example of where the usual conduct of such course may not apply at times. It is a microcosm in that it contains the same structure that is typical of asynchronous online courses with a corresponding group of students possessing disparate abilities and interests. However, due to the extreme time differences between the students, the course cannot be conducted in a typical fashion and needs to be modified accordingly.

To that end, with the importance of timely communication being paramount, students need to be advised of the requirement of timely delivery of documents with an accurate timestamp. The students still possess some control in their communications, as they have been allowed to use a means of communications that is acceptable to all and adhere to their own rules. Also, a timely post to the discussion forum at a time that is as convenient as possible to all is critical. With being on opposite ends of the globe quite possible, the students need to have the discipline to promptly respond to posts, e-mails, and chats, always keeping in mind the implications of being late and how it can impact many other people as well as themselves. A majority of students had little or no problem with this, while only a few voiced some relatively minor difficulties in the course reviews.

This course has been an example of how high-speed Internet communications with impartial enforcement of rules of conduct allow an asynchronous online course to be conducted fairly and efficiently even if the students are dispersed around the globe at an extreme. Thus, both the technical and pedagogical aspects need to be properly established and administered for the sole purpose of the course to be accomplished. Of course, that purpose is learning.

\section{References}

Brindley, J., Blaschke, L., \& Walti, C. (2009). Creating effective collaborative learning groups in an online environment. The International Review of Research in Open and Distributed Learning, 10. Retrieved from http://www.irrodl.org/index.php/irrodl/article/view/675/1271

Churcher, K. M. A., Downs, E., \& Tewksbury, D. (2014). "Friending" Vygotsky: A social constructivist pedagogy of knowledge building through classroom social media use. The Journal of Effective Teaching, 14, 33-50.

Doolittle, P .E. (1999). Constructivism and online education. Paper presented at the International Online Conference: Teaching Online in Higher Education, Fort Wayne, IN. Retrieved January 26, 2011, from http://web.archive.org/web/200612080709111http:/ledpsychserver.ed. vt.edulworkshops/tohe1999Itext/do02.pdf

Gagne, R. M., \& Briggs, L. J. (1979). Principles of instructional design (2nd ed.). New York, NY: Holt, Rinehart, \& Winston. 
Jacobs, P. (2014). Engaging students in online courses. Research in Higher Education Journal, 26. Retrieved from http://files.eric.ed.gov/fulltext/EJ1055325.pdf

Kear, K., Donelan, H., \& Williams, J. (2014). Using wikis for online group projects: Student and tutor perspectives. International Review of Research in Open and Distance Learning, 15. Retrieved from http://www.irrodl.org/index.php/irrodl/article/view/1753

Marino, K., \& Warner, J. (2014). Social presence in student international collaboration projects. In T. Bastiaens (Ed.), Proceedings of E-Learn: World Conference on E-Learning in Corporate, Government, Healthcare, and Higher Education 2014 (pp. 1277-1284). Chesapeake, VA: Association for the Advancement of Computing in Education.

Morgan, K., Williams, K., Cameron, B., \& Wade, C. (2014). Faculty perceptions of online group work. The Quarterly Review of Distance Education, 15, 37-41.

Paulus, T. M. (2005). Collaborative and cooperative approaches to online group work: The impact of task type. Distance Education, 26, 111-125.

Roberts, T. S., \& McInnerney, J. M. (2007). Seven problems of online group learning (and their solutions). Educational Technology \& Society, 10, 257-268.

Soon, L., \& Fraser, C. (2011). Knowledge sharing and knowledge exchange in distance education online group work. International Journal of Information and Education Technology, 1, 156162.

Strickland, J., Strickland, A., Wang, P., Zimmerly, L., \& Moulton, S. (2013). Online course development using the ADDIE instruction design model: The need to establish validity. In R. McBride \& M. Searson (Eds.), Proceedings of Society for Information Technology \& Teacher Education International Conference 2013 (pp. 2651-2658). Chesapeake, VA: Association for the Advancement of Computing in Education.

Vygotsky, L. S. (1978). Mind in society. Cambridge, MA: Harvard University Press.

Wang, Y. D. (2014). Applying constructivist instructional strategies to e-learning: A case study of a Web development course. International Journal on E-Learning. 13, 375-406.

Williams, K. C., Cameron, B. A., \& Morgan, K. (20 I2). Supporting online group projects. North American College Teachers of Agriculture Journal, 56, 15-20.

The Journal of Educational Research and Practice provides a forum for studies and dialogue that allows readers to better develop social change in the field of education and learning. Journal content may focus on educational issues of all ages and in all settings. It also presents peer-reviewed commentaries, book reviews, interviews of prominent individuals, and additional content. The objectives: We publish research and related content that examines current relevant educational issues and processes aimed at presenting readers with knowledge and showing how that knowledge can be used to impact social change in educational or learning environments. Additional content provides an opportunity for scholarly and professional dialogue regarding that content's usefulness in expanding the body of scholarly knowledge and increasing readers' effectiveness as educators. The journal also focuses on facilitating the activities of both researcher-practitioners and practitioner-researchers, providing optimal opportunities for interdisciplinary and collaborative thought through blogging and other communications.

Walden University Publishing: http://www.publishing.waldenu.edu 